\title{
BMJ Open Residential mobility for a national cohort of New Zealand-born children by area socioeconomic deprivation level and ethnic group
}

\author{
Oliver Robertson (D) ,' Kim Nathan (D) , ${ }^{1}$ Philippa Howden-Chapman, ${ }^{1}$ \\ Michael George Baker, ${ }^{1}$ Polly Atatoa Carr, ${ }^{2}$ Nevil Pierse ${ }^{1}$
}

To cite: Robertson 0 , Nathan K, Howden-Chapman P, et al. Residential mobility for a national cohort of New Zealand-born children by area socioeconomic deprivation level and ethnic group. BMJ Open 2021;11:e039706. doi:10.1136/ bmjopen-2020-039706

- Prepublication history for this paper is available online. To view these files, please visit the journal online (http://dx.doi. org/10.1136/bmjopen-2020039706).

Received 23 April 2020 Revised 10 November 2020 Accepted 18 November 2020

Check for updates

(C) Author(s) (or their employer(s)) 2021. Re-use permitted under CC BY-NC. No commercial re-use. See rights and permissions. Published by BMJ.

${ }^{1}$ Department of Public Health, University of Otago, Wellington, New Zealand

${ }^{2}$ National Institute of

Demographic and Economic

Analysis, University of Waikato, Hamilton, New Zealand

Correspondence to

Dr Oliver Robertson;

oliver.robertson@otago.ac.nz

\section{ABSTRACT}

Objectives The aims of this study are to describe area deprivation levels and changes that occur during residential moves involving New Zealand children from birth to their fourth birthday, and to assess whether these changes vary by ethnicity.

Design Longitudinal administrative data.

Setting Children born in New Zealand from 2004 to 2018. Participants All (565 689) children born in New Zealand with at least one recorded residential move.

Outcome measures A longitudinal data set was created containing lifetime address histories for our cohort. This was linked to the New Zealand Deprivation Index, a measure of small area deprivation. Counts of moves from each deprivation level to each other deprivation level were used to construct transition matrices.

Results Children most commonly moved to an area with the same level of deprivation. This was especially pronounced in the most and least deprived areas. The number of moves observed also increased with deprivation. Māori and Pasifika children were less likely to move to, or remain in low-deprivation areas, and more likely to move to high-deprivation areas. They also had disproportionately high numbers of moves.

Conclusion While there was evidence of mobility between deprivation levels, the most common outcome of a move was no change in area deprivation. The most deprived areas had the highest number of moves. Māori and Pasifika children were over-represented in high-deprivation areas and under-represented in lowdeprivation areas. They also moved more frequently than the overall population of 0 to 3 year olds.

\section{INTRODUCTION}

Changes of home address and frequent residential mobility can have negative impacts on young children, with possible long-term consequences for their physical and mental health, and social outcomes. ${ }^{1-4}$ However, there are also potential benefits from mobility in some instances. For example, families may be upwardly mobile and move to areas with better access to jobs and higher quality housing, reflecting increasing socioeconomic
Strengths and limitations of this study

- Use of administrative data captures all residential moves made by children from birth until their fourth birthday.

- These data capture frequent moves and movers, often missed by survey or census data studies.

- Highlights high rate of early residential instability for Māori and Pasifika children in New Zealand.

- Describes the frequency and patterns of residential mobility within and between deprivation levels.

- Excludes New Zealand residents born outside the country.

resources and opportunities. ${ }^{5}$ Understanding the broad trends in moves and differentiating between moves to areas which are likely to be associated with either 'positive' or 'negative' consequences are therefore important questions in the residential mobility literature, with implications for public policy and children's health and well-being. ${ }^{6}$ Moreover, understanding the patterns of movement of patients, and especially children, is a challenge for clinicians and has important implications for both primary and secondary healthcare.

Neighbourhood economic and social contexts, physical environments and availability of resources such as health amenities have implications for health. ${ }^{7}$ Suggested pathways by which area deprivation affects child health and well-being include limited access to resources such as health and social services, witnessing violence, and experiencing 'chaos, disorder and isolation' along with parental stress. ${ }^{8}$ Blair and colleagues also suggested environmental factors such as a lack of safe play areas, poor schools and exposure to pollutants. ${ }^{9}$

Specifically, neighbourhood or area-level socioeconomic deprivation is associated with 
several child health outcomes, ${ }^{10}$ including increased risk for asthma, ${ }^{11}{ }^{12}$ obesity, ${ }^{13}$ influenza hospitalisations, ${ }^{14}$ antisocial behaviour, ${ }^{15}$ poor sleep ${ }^{16}$ and injury. ${ }^{17}$ In New Zealand, socioeconomic deprivation is also a known driver of health inequalities, with increased rates of acute rheumatic fever and potentially avoidable hospitalisations for populations living in areas of deprivation compared with those in areas of socioeconomic advantage. ${ }^{18} 19$

There is also evidence that living in socioeconomically advantaged neighbourhoods promotes positive outcomes. For example, Bruckner, Kane and Gailey found that mothers' upward mobility decreased the likelihood of preterm birth. ${ }^{20}$ While Moving to Opportunity shows a potentially positive effect on future earnings for children who moved before 13 years of age, it and other initiatives that facilitate moves to lower deprivation neighbourhoods have had generally mixed results. ${ }^{5}$

Increased probabilities of residential mobility and moving to, or staying in, areas of high socioeconomic deprivation, have been associated with ethnicity both internationally and in New Zealand. ${ }^{21-24}$ In New Zealand, Māori and Pasifika populations face economic disadvantage, with lower average incomes and employment rates, ${ }^{25}$ and lower rates of home ownership. ${ }^{26}{ }^{27}$ They also face discrimination in the rental market, ${ }^{28}$ move frequently within high-deprivation areas, ${ }^{22} 2329$ and are more likely to live in cold or damp housing, ${ }^{30}$ with stark and persistent health inequalities. ${ }^{31} 32$

New Zealand has a highly mobile population, with $39 \%$ of people residing at a different address in the 2013 Census compared with the 2006 Census, ${ }^{33}$ and annual internal migration rates from 2008 to 2016 of between $4.5 \%$ and $4.8 \%{ }^{34}$ Children under the age of 5 years have one of the highest mobility rates. ${ }^{35-37}$ In a recent study of early childhood mobility, more than two-third $(69 \%)$ of New Zealand children ( $n=313164)$ had moved at least once by the age of four and $12 \%$ had experienced four or more moves. ${ }^{2}$ Among the Growing Up in New Zealand longitudinal study of over 6000 New Zealand children, $33 \%$ were living in high-deprivation areas at 4 years of age as measured by the New Zealand Deprivation Index (NZDep)..$^{38}$

\section{Current study}

Our study focusses on the patterns of moves made by children from birth to their fourth birthday, to and from areas of varying socioeconomic deprivation. Many previous studies in this area have made use of longitudinal surveys and census data. ${ }^{22} 39$ Although important, these only capture address data at particular time points, potentially missing high-frequency, short-duration moves. Our population of interest will also be missing from any analysis using data collected too far apart, such as 5 yearly census data. ${ }^{29}$ In this descriptive analysis, we use the Integrated Data Infrastructure (IDI), a set of linked government administrative data sets compiled by Statistics New Zealand, to construct a longitudinal address data set containing lifetime address histories for our cohort.
The current descriptive study grew out of work on health and social outcomes associated with residential mobility in early childhood. ${ }^{2}$ Taking a developmental approach, the prior study focussed on the first 4 years of life based on both the importance of this period for healthy child development and the frequency with which young children move. Whereas this earlier work focussed on child outcomes associated with mobility, the current study examines the patterns and transitions of the moves themselves, using a similar cohort. This study provides a descriptive analysis of the movement patterns of children born in New Zealand between 2004 and 2018, from birth to their fourth birthday.

The population patterns of movement are also presented for Pasifika and Māori children. This ethnic breakdown is of interest as these populations have significant health and income inequities, lower rates of home ownership, and high rates of residential mobility. By focussing on the level of deprivation in the areas moved from (the origin), and the level of deprivation in the areas moved to (the destination), we show the extent to which moves represent transitions between deprivation areas, and the proportion of moves that are towards areas of similar, greater, or lesser socioeconomic deprivation.

To summarise, the aims of this study are to describe levels of neighbourhood deprivation and changes that occur during residential moves involving New Zealand children 0 to 3 years of age, and to assess whether these changes vary by ethnicity.

\section{METHODS}

Our data set of addresses is created using the full address notification table within the IDI. ${ }^{40}$ The NZDep2013 is used as the small area measure of socioeconomic deprivation at each address. ${ }^{41}$ Our cohort is all children born in New Zealand from 2004 to 2018, and we use all address data that is recorded before their fourth birthday, up to February 2019.

The IDI is a collection of primarily government data sets, including birth records, hospitalisations and census data, that have been de-identified and linked at the individual level by Statistics New Zealand.$^{42}$ In identifying the ethnicities of our cohort, we have used the source ranked ethnicity table within the IDI. This combines ethnicity data from a number of different sources and ranks their estimated reliability in selecting each individual's ethnicities. ${ }^{43}$ In our analysis, we have used total response ethnicity, enabling each individual to identify with more than one ethnic group. ${ }^{44}$

Address data within the IDI are sourced from six government agencies, the Ministry of Health, Ministry of Social Development, Ministry of Education, Accident Compensation Corporation, Inland Revenue Department, and Statistics New Zealand. ${ }^{40}$ The address notification table is updated any time an individual interacts with one of these organisations and their address information has changed. This is logged as an entry in the full address notification 


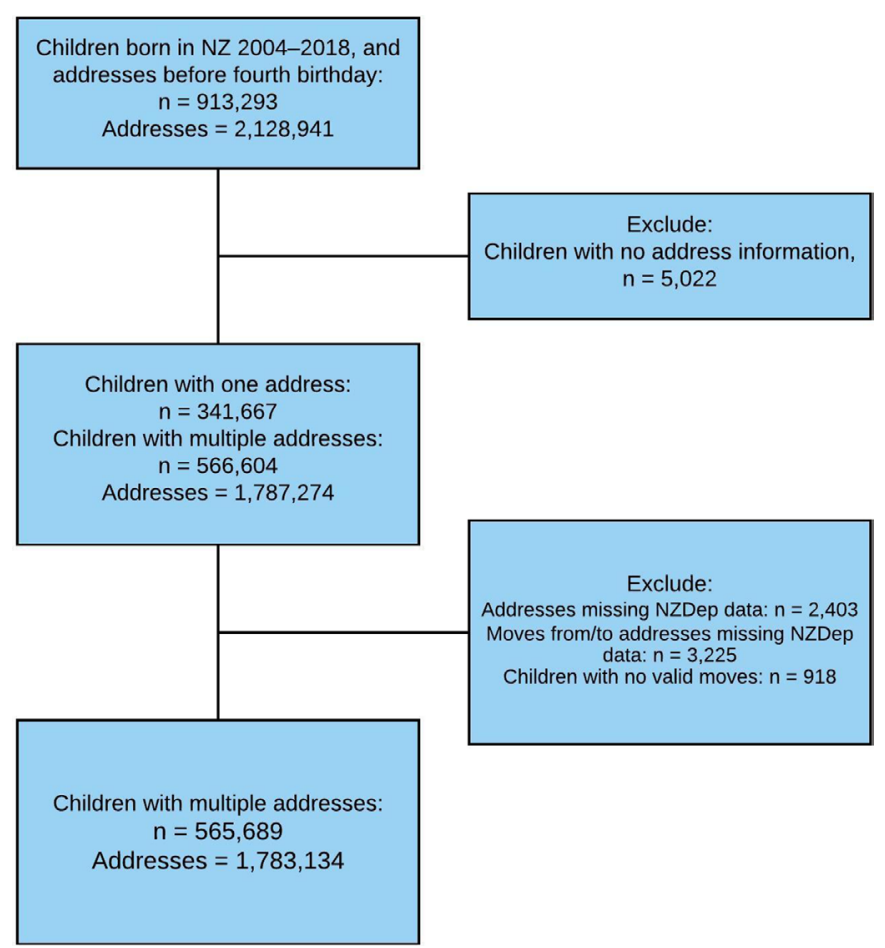

Figure 1 Data set creation process based on children born in NZ from 2004 to 2018 with valid address information. NZ, New Zealand; NZDep, New Zealand Deprivation Index.

table, containing the unique property ID, the date the address change was provided, and information on the meshblock and territorial authority where the address is located. A meshblock is the smallest geographic unit used by Statistics New Zealand. Meshblock sizes vary, but they usually have 30 to 60 dwellings and approximately 60 to 120 residents. ${ }^{45}$ The meshblock information associated with each address allows us to link it to its area deprivation level, as reported in NZDep2013.

The address table contains repeated data, where the same address appears multiple times for an individual. Given the frequency with which this occurs, it seems likely that most of these updates are not real moves but are instead artefacts of the administrative system used to generate the table. Therefore, multiple moves to the same address were excluded, while keeping the earliest occurrence of each address ID for individuals.

NZDep is a small area socioeconomic deprivation index created using census data. As described by Atkinson, Salmond and Crampton, individual or small groups of meshblocks are ranked in terms of area deprivation and then given a decile-based NZDep score from one to ten. ${ }^{41}$ For NZDep2013 the deprivation rankings are based on nine variables: access to the internet, benefit receipt, income level, employment status, education, owning their dwelling, living in a single-parent family, household crowding and access to a car. A meshblock with an NZDep score of 1 is in the $10 \%$ of least deprived areas, and a meshblock with an NZDep score of 10 is in the $10 \%$ of most deprived areas.
While there are versions of NZDep based on the 2006 and 2018 Censuses, we have chosen to solely use NZDep2013 across all our analyses. It sits roughly in the middle of our data and, as each version of NZDep uses different variables in measuring deprivation and is based on potentially different meshblock boundaries, using only NZDep 2013 allows us to maintain a consistent metric over the period of the study.

There are some meshblocks in our address table that have no associated NZDep2013 decile. This occurred when there were insufficient individuals living in that particular meshblock and the neighbouring meshblocks to generate the metric, or if there were no residents when the census was conducted in $2013 .^{41}$ Moves to or from meshblocks that have no known NZDep decile have been removed from our data set. Figure 1 illustrates this process, showing what data have been removed, are missing and the resulting sample sizes.

To construct the transition matrices, we counted the number of moves from each area deprivation level to each other area deprivation level. As we are looking at the number of moves and not the number of individuals, individuals can be counted multiple times if they are frequent movers. Total response ethnicity is used in all analyses, enabling individuals to identify as multiple ethnicities. ${ }^{46}$

\section{Patient and public involvement}

There was no patient involvement. The data used were de-identified government administrative data.

\section{RESULTS}

\section{Study population}

Demographic information for the children in our cohort, non-moving children from the IDI, and the same age group from the 2013 Census, is shown in table 1. In our cohort of movers, $33.5 \%$ identify as Māori, and $17.0 \%$ as Pasifika, both larger proportions than reported in the 2013 Census (24.4\% and $13.0 \%$, respectively). However, the non-moving group has a smaller proportion identifying as either Māori or Pasifika, so at least some of the observed difference is due to Māori and Pasifika children being over-represented in the population that move, and under-represented in the non-mover population.

In table 1, we also see that in the IDI cohort that move, both Māori and Pasifika move more frequently than the cohort as a whole. If we include the non-mover population, these differences increase further due to the over-representation of Māori and Pasifika in the mover population. Including the non-movers, the population as a whole has 1.33 moves per child, while Māori move 1.84 times and Pasifika move 1.53 times.

\section{Residential moves for child population}

Table 2 is the transition matrix for all children in our cohort, with the left column indicating the NZDep decile of the origin address, and the top row indicating the NZDep decile of the destination address. The cells show 


\begin{tabular}{|c|c|c|c|}
\hline & IDI movers & IDI non-movers & 2013 Census \\
\hline Population & 565689 & 341667 & 292041 \\
\hline Male & $51.6 \%$ & $51.0 \%$ & $51.1 \%$ \\
\hline Female & $48.4 \%$ & $49.0 \%$ & $48.9 \%$ \\
\hline Māori & $33.5 \%$ & $20.4 \%$ & $24.3 \%$ \\
\hline Pasifika & $17.0 \%$ & $12.8 \%$ & $13.0 \%$ \\
\hline $\begin{array}{l}\text { Moves per } \\
\text { child }\end{array}$ & 2.15 & - & - \\
\hline $\begin{array}{l}\text { Moves per } \\
\text { child (Māori) }\end{array}$ & 2.52 & - & - \\
\hline $\begin{array}{l}\text { Moves } \\
\text { per child } \\
\text { (Pasifika) }\end{array}$ & 2.24 & - & - \\
\hline
\end{tabular}

IDI, Integrated Data Infrastructure.

the percentage of moves from each origin deprivation level to each destination level. The move count column shows the number of moves from meshblocks, and movers is the number of individuals that contributed moves, to each level of deprivation in our data set. The non-movers column shows the number of children who lived in an area of that level of deprivation and did not move. The rightmost column, census population, shows the number of children living in each deprivation level on the night of the 2013 Census. This is included to show the distribution of children over deprivation levels at a moment in time.

Table 2 shows that the count of moves and movers by origin deprivation level is strictly increasing with the level of deprivation, with NZDep 10 having the largest number of both moves and movers. It also has the highest level of churn, with 1.25 moves per potential mover (moves divided by movers plus non-movers). Examining the highlighted diagonal of the transition matrix in table 2, we can see that for every origin level of deprivation, the most frequent outcome is a move to an area within the same deprivation decile. This is especially prominent in the most-deprived and least-deprived areas, which have the largest percentage of moves to meshblocks of the same deprivation decile.

The population of non-moving children is relatively evenly distributed over the different levels of deprivation. However, movers and children on the night of the 2013 Census increase with the level of deprivation. A $\chi^{2}$ test of the distribution of non-moving children with the census night population shows a statistically significant difference $(p<0.001)$. This indicates that the non-mover population is systematically different from the population as a whole.

\section{Residential moves stratified by ethnicity}

Table 3 is the transition matrix for Māori children in our cohort and table 4 contains the transitions for Pasifika children. For the Māori population, moves from the six

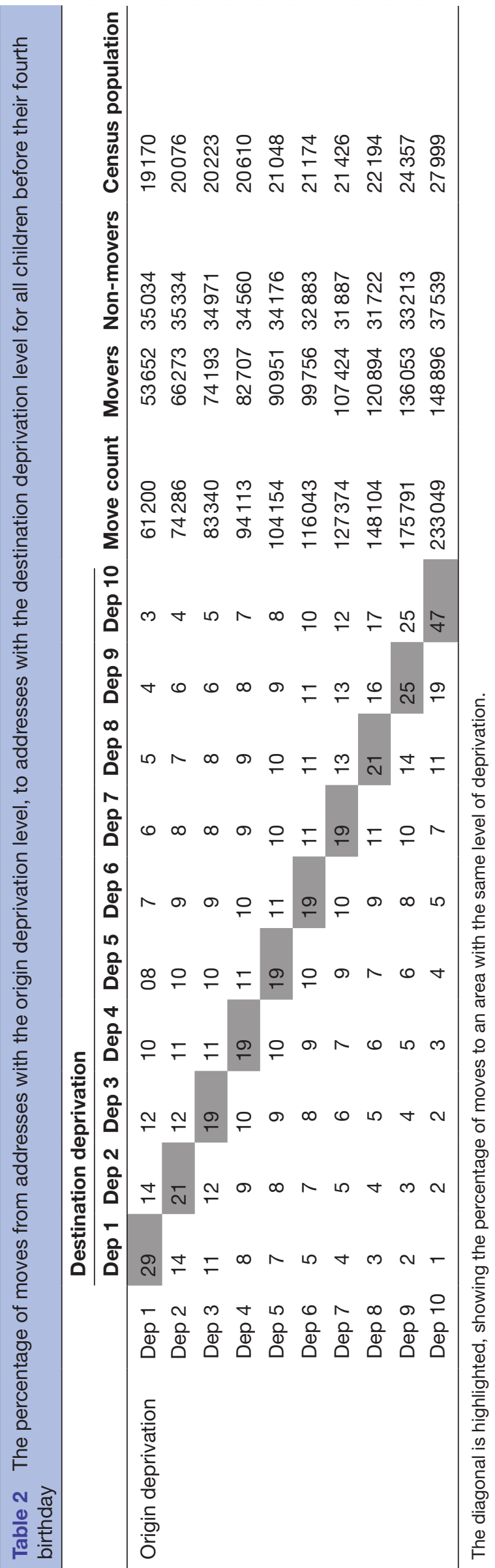




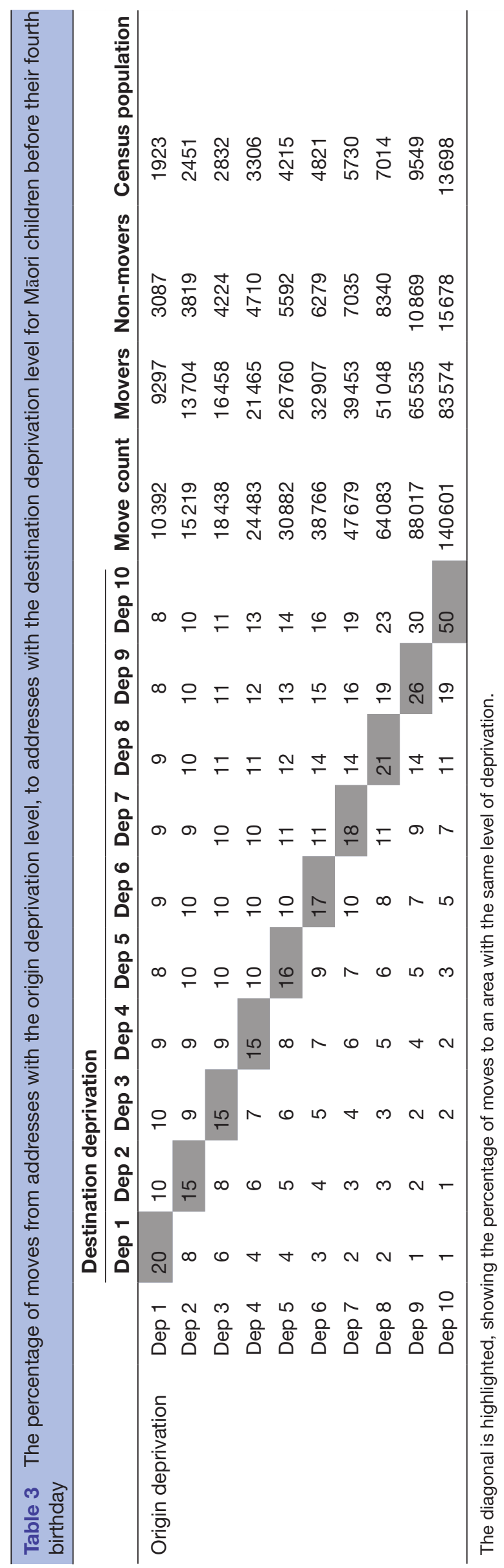

least deprived NZDep deciles ${ }^{1-6}$ are most likely to be to meshblocks with the same deprivation decile. However, moves from the more deprived areas ${ }^{7-10}$ are more likely to be to an NZDep 10 area than to a meshblock with the same deprivation level.

For the Pasifika population, an even larger portion of the origin deprivation deciles are most likely to result in moves to NZDep 10 areas. Table 4 shows that only those Pasifika children moving from NZDep 1 areas are most likely to move to an area with the same level of deprivation, and moves from any other level of deprivation are most likely to be to an NZDep 10 area. For Pasifika children, the percentage of moves to the same level of deprivation is also lower for the less deprived areas than that seen for the total population, and the proportion of moves to more deprived areas is higher. The percentage of moves from NZDep 10 to another NZDep 10 meshblock for Pasifika children is also larger; $50 \%$ of moves from NZDep 10 for Māori and 54\% for Pasifika children are to another NZDep 10 area. This compareswith $47 \%$ of moves for the entire 0 to 3 years old population.

Both the Māori and Pasifika cohorts are likely to move into the most deprived areas. For any level of deprivation, the percentage of moves to NZDep 10 is larger than that observed for the full cohort. Māori and Pasifika children are also less likely to move into areas with the least arealevel socioeconomic deprivation. ${ }^{27}$ The percentage of moves from any level of deprivation to NZDep 1 is lower in table 3 than in table 2, except in the case of moves from NZDep 10 to NZDep 1, where it is equal, at $1 \%$. Using $\chi^{2}$ tests to compare the distribution of moves for each origin level of deprivation, we found the differences between Māori, Pasifika and the whole population were statistically significant $(\mathrm{p}<0.001)$ in every case.

The number of moves involving Māori or Pasifika individuals also strictly increases with the level of socioeconomic deprivation. While this matches the results for the whole cohort as shown in tables 2-4 also show that Māori and Pasifika make up a disproportionately high fraction of the moves associated with very deprived areas, and a disproportionately low fraction of moves associated with areas with low levels of deprivation. In our sample, $28.5 \%$ of the children were Māori but they made up only $17 \%$ of the moves from NZDep 1 areas, and $60 \%$ of the moves from NZDep 10 areas. Similarly, $15.4 \%$ of the cohort children were Pasifika, and yet they only made $5.4 \%$ of the moves from NZDep 1 areas, and $33.7 \%$ of the moves from NZDep 10 meshblocks.

When looking at moves made per child in the most and least deprived areas (moves divided by movers plus nonmovers), we find that Māori and Pasifika children living in NZDep 1 areas move more frequently than the total population (0.83 and 0.84 vs 0.69 ). In NZDep 10 areas, Māori children move more frequently (1.42 vs 1.25$)$, but Pasifika children actually move less frequently (1.20), so their over-representation in moves is driven by the number of children living in the most deprived areas, rather than frequent moving. 
DISCUSSION

\section{Main findings}

Our results show some important patterns in the mobility of NZ-born children, which have important consequences for social mobility and health. ${ }^{2}$ By definition, each of the deprivation deciles have approximately equal numbers of people living in them. However, our results show that movers and the count of moves increases steadily with deprivation. Our results are broadly similar to those in Flouri, Mavroveli and Midouhas, ${ }^{39}$ and Morrison and Nissen; more moves occur from higher deprivation areas, and more children live in these areas. ${ }^{22}$ However, our study shows a distinct increase at each level of deprivation, and while these previous studies also observed a similar trend, in our results the relationship is much clearer. This difference is due to our use of detailed administrative data versus the survey and census data used in the previous papers, which allow us to capture a larger number of the moves made, and to show that there is greater neighbourhood churn at higher levels of deprivation. Lower home ownership and insecure rental leases in higher deprivation areas are likely to contribute to this. ${ }^{27}$

For the full cohort of children, the most likely NZDep destination is the same as the origin. As most residential moves are of a short distance, and NZDep is spatially correlated with similar levels of deprivation in neighbouring meshblocks, ${ }^{47}$ this is not a surprising result. However, this result is especially marked when looking at both the most and least deprived areas. The percentage of moves from NZDep 1 (the least deprived) to another NZDep 1 meshblock is the second highest at 29\%, while the highest occurs for moves from and to NZDep 10, at $47 \%$. In comparison, $19 \%$ of moves from NZDep 3-7 are to an area with the same level of deprivation, implying that there are other underlying factors that contribute to the high rates of same decile moves for the most and least deprived areas.

For Māori children moving from less deprived areas (NZDep 1 to 6 ), the most likely outcome is moving to an area with the same level of deprivation. However, if they are moving from a more deprived area (NZDep 7 to 10), their most likely outcome is moving to one of the most deprived area (NZDep 10). For Pasifika children, only those in the least deprived areas (NZDep 1) are likely to move to an area with the same level of deprivation. For every other origin level of deprivation, their most likely destination is one of the most deprived areas (NZDep 10).

Looking at the counts of unique individuals that live in each level of deprivation we see the same pattern, that is, Māori and Pasifika children are over-represented in the highly deprived areas and under-represented in lowdeprivation areas. While the non-moving population as a whole was evenly distributed, the number of non-moving Māori and Pasifika increased with the level of deprivation.

Our results show very high levels of movement for both Māori and Pasifika children, and these moves are overwhelmingly occurring in high-deprivation areas. For these children, most moves are towards greater socioeconomic 
deprivation; once in very deprived areas, it is less likely that they will leave them. This is of concern as these communities already have lower income, worse health, and poorer education outcomes. ${ }^{48}$ A number of factors contribute to the high rates of mobility among Māori and Pasifika, including low rates of home ownership and lower levels of income. ${ }^{49}$ In the 2018 Census, $69 \%$ of Māori and $79 \%$ of Pasifika lived in households that did not own their dwelling, compared with $48.2 \%$ for the entire population, ${ }^{48}$ and the Ministry of Social Development found that in 2018, the median household income in New Zealand was 39 900, while for Māori it was 32200 and for Pasifika $30400 .^{50}$

While residential mobility and living in deprived areas have been shown to have negative health impacts, ${ }^{10} 1118$ there are also distinct inequalities in health outcomes for Māori and Pasifika compared with the wider population. From 2004 to 2008, Māori and Pasifika were shown to have higher rates of infectious disease, with rate ratios of 2.15 and 2.35, respectively. ${ }^{31}$ They are also dramatically over-represented in the population that develop acute rhumatic fever, with $51.7 \%$ of cases in those younger than 20 years being Māori, and $43.4 \%$ being Pasifika. ${ }^{51}$ As of 2019, the Labour coalition government's policy is to improve the homes and communities in socioeconomically deprived areas. A number of progressive home ownership schemes, as well as policies that improve rental standards and tighten the rules for terminating tenancies, have been announced. ${ }^{52-54}$

\section{Limitations and further research needs}

An issue with the address notification data, along with much of the administrative data contained in the IDI, is that addresses are only observed for an individual when they interact with one of the six agencies described above and provide new address details. ${ }^{55}$ Differences in the rates with which different groups interact with government agencies could lead to systematic differences and biases that are difficult or impossible to observe and control for using the data available.

Statistics New Zealand found that there was a $79 \%$ match between address meshblock information in the 2013 Census and an individual's most up-to-date IDI address. ${ }^{40}$ We expect this to be the minimum level of accuracy for our study, as the Census data only captures address updates to a point in time, whereas the IDI will record if they ever update at a particular address.

As our cohort is defined as children born in New Zealand, we are missing the residential mobility experienced by young refugees, immigrants, and New Zealanders born overseas. Analysis of the movement patterns of these groups would make a worthwhile extension of this project. It is also possible that different patterns of moves may occur among older children and adolescents, and we plan to address this in the future.

\section{CONCLUSION}

The implications of household moves for children remain an important question in the residential mobility literature-are moves good or bad? Moves towards economic opportunity, family connections or greater amenities are likely to have positive impacts on children and families. On the other hand, moves can also disrupt existing social support networks, or be to more deprived areas with potentially fewer amenities and less access to resources. While many of these factors cannot be accurately measured using government administrative data, we can assess the level of deprivation in the origin and destination meshblocks. This does not capture all of the subtleties associated with the quality of a move, but it does give us some information on whether moves are positive, that is, moving to or staying in low-deprivation areas, or negative, that is, staying in or moving to highly deprived meshblocks.

Our results show that while there is a reasonable amount of mobility in terms of area deprivation, the most likely outcome of a move is to an area with the same level of deprivation. This is especially true for the most deprived areas, meaning that children are most likely to remain in high levels of deprivation (NZDep 8 to 10). Areas of high deprivation also have the highest levels of churn, and children living there are more likely to remain in these areas.

The results in this paper show that Māori and Pasifika children, on average, move more frequently than the group of all children aged 0 to 3 years and have lower levels of upward residential mobility than the cohort of all children. They are more likely to move into, and to remain in, areas of high deprivation, and are especially likely to move to the most deprived areas. Māori and Pasifika children are over-represented in high-deprivation areas, and under-represented in the low-deprivation areas, given the sizes of their respective cohorts.

Overall, these findings on patterns of residential moves among New Zealand children indicate that residential moves predominantly occur within areas of similar deprivation and highlight the unequal proportion of moves into, and within, high-deprivation areas for Māori and Pasifika children. This study suggests that policy interventions that promote stability, particularly in Māori and Pasifika families, should be considered.

Acknowledgements We thank Dr Sheree Gibb for her help with the Integrated Data Infrastructure, especially with regards to the address data.

Contributors OR: Performed the data analysis and led the writing of the paper. $\mathrm{KN}$ : Provided significant input into the research question, and contributed to the writing and editing. PHC: Helped shape the research question and direction and contributed significantly to the writing and editing of the paper. MGB: Helped shape the research question and direction and contributed significantly to the writing and editing of the paper. PAC: Helped shape the research question and direction and contributed significantly to the writing and editing of the paper. NP: Supervised this research. He helped to shape the research question and provided significant input into the writing and editing.

Funding The authors have not declared a specific grant for this research from any funding agency in the public, commercial or not-for-profit sectors.

Disclaimer The results in this report are not official statistics. They have been created for research purposes from the Integrated Data Infrastructure (IDI), managed by Statistics New Zealand. The opinions, findings, recommendations and conclusions expressed in this article are those of the authors, not Statistics New Zealand. Access to the anonymised data used in this study was provided by 
Statistics New Zealand under the security and confidentiality provisions of the Statistics Act 1975 . Only people authorised by the Statistics Act 1975 are allowed to see data about a particular person, household, business or organisation, and the results in this article have been confidentialised to protect these groups from identification and to keep their data safe. Careful consideration has been given to the privacy, security and confidentiality issues associated with using administrative and survey data in the IDI. Further detail can be found in the privacy impact assessment for the IDI available online (www. stats.govt.nz).

\section{Competing interests None declared.}

Patient and public involvement Patients and/or the public were not involved in the design, or conduct, or reporting, or dissemination plans of this research.

\section{Patient consent for publication Not required.}

Ethics approval The Human Ethics Committee (Health), University of Otago (HD17/005). Statistics New Zealand (MAA2017-19).

Provenance and peer review Not commissioned; externally peer-reviewed.

Data availability statement Data may be obtained from a third party and are not publicly available. Our data is deidentified administrative data stored within the Integrated Data Infrastructure. This database is managed by Statistics New Zealand, and can be accessed from within datalabs run by them. Access is provided by Statistics New Zealand after an application process. For information on how to access this data see:https://www.stats.govt.nz/integrated-data/integrated-datainfrastructure/or email access2microdata@stats.govt.nz.

Open access This is an open access article distributed in accordance with the Creative Commons Attribution Non Commercial (CC BY-NC 4.0) license, which permits others to distribute, remix, adapt, build upon this work non-commercially, and license their derivative works on different terms, provided the original work is properly cited, appropriate credit is given, any changes made indicated, and the use is non-commercial. See: http://creativecommons.org/licenses/by-nc/4.0/.

\section{ORCID iDs}

Oliver Robertson http://orcid.org/0000-0001-6807-8865

Kim Nathan http://orcid.org/0000-0002-0503-0263

\section{REFERENCES}

1 Morris T, Manley D, Northstone K, et al. How do moving and other major life events impact mental health? A longitudinal analysis of UK children. Health Place 2017;46:257-66.

2 Nathan K, Robertson O, Atatoa Carr P, et al. Residential mobility and socioemotional and behavioural difficulties in a preschool population cohort of new Zealand children. J Epidemiol Community Health 2019;73:947-53.

3 Hughes $\mathrm{CH}$, Baumer $\mathrm{JH}$. Moving house: a risk factor for the development of childhood asthma? BMJ 1995;311:1069-70.

4 Jelleyman T, Spencer N. Residential mobility in childhood and health outcomes: a systematic review. J Epidemiol Community Health 2008;62:584-92.

5 Chetty R, Hendren N, Katz LF. The effects of exposure to better neighborhoods on children: New evidence from the Moving to Opportunity experiment. Am Econ Rev 2016;106:855-902.

6 Gambaro L, Joshi H, Lupton R. Moving to a better place? Residentia mobility among families with young children in the millennium cohort study. Popul Space Place 2017;23:e2072.

7 Stafford M, McCarthy M. Neighbourhoods, housing, and health. Social determinants of health 2006;2:297-317.

8 Shanks T, Danziger SK. Anti-poverty policies and programs for children and families. Social policy for children and families: a risk and resilience perspective, 2010: 25-6.

9 Blair M, Stewart-Brown S, Waterston T. Child public health. Oxford University Press, 2010

10 Leventhal T, Brooks-Gunn J. The neighborhoods they live in: the effects of neighborhood residence on child and adolescent outcomes. Psychol Bull 2000;126:309-37.

11 Cantu P, Kim Y, Sheehan C, et al. Downward neighborhood poverty mobility during childhood is associated with child asthma: evidence from the geographic research on wellbeing (grow) survey. J Urban Health 2019:96:558-69.

12 Simons E, Dell SD, Moineddin R, et al. Neighborhood material deprivation is associated with childhood asthma development: analysis of prospective administrative data. Can Respir $J$ 2019;2019:1-7.

13 Twaits A, Alwan NA. The association between area-based deprivation and change in body-mass index over time in primary school children: a population-based cohort study in Hampshire, UK. Int J Obes 2020;44:628-36.

14 Yousey-Hindes KM, Hadler JL. Neighborhood socioeconomic status and influenza hospitalizations among children: new Haven County, Connecticut, 2003-2010. Am J Public Health 2011;101:1785-9.

15 Odgers CL, Caspi A, Russell MA, et al. Supportive parenting mediates neighborhood socioeconomic disparities in children's antisocial behavior from ages 5 to 12. Dev Psychopathol 2012;24:705-21.

16 Bagley EJ, Fuller-Rowell TE, Saini EK, et al. Neighborhood economic deprivation and social fragmentation: associations with children's sleep. Behav Sleep Med 2018;16:542-52

17 Poulos R, Hayen A, Finch C, et al. Area socioeconomic status and childhood injury morbidity in New South Wales, Australia. Inj Prev 2007;13:322-7.

18 Craig E, Anderson P, Jackson G, et al. Measuring potentially avoidable and ambulatory care sensitive hospitalisations in New Zealand children using a newly developed tool. N Z Med J 2012;125:38-50

19 Milne RJ, Lennon DR, Stewart JM, et al. Incidence of acute rheumatic fever in New Zealand children and youth. J Paediatr Child Health 2012;48:685-91.

20 Bruckner TA, Kane JB, Gailey S. Strong upward neighborhood mobility and preterm birth: a matched-sibling design approach. Ann Epidemiol 2019;36:48-54.

21 Finney N. Understanding ethnic differences in the migration of young adults within Britain from a lifecourse perspective. Transactions of the Institute of British Geographers 2011;36:455-70.

22 Morrison PS, Nissen K. Moving in and out of areas of deprivation: evidence from the New Zealand census. New Zealand population review 2010;36:55

23 Clark WAV, Morrison PS. Socio-spatial mobility and residential sorting: evidence from a large-scale survey. Urban Studies 2012;49:3253-70.

24 Quillian L. How long are exposures to poor neighborhoods? The long-term dynamics of entry and exit from poor neighborhoods. Popul Res Policy Rev 2003;22:221-49.

25 Marriott L, Sim D. Indicators of inequality for Māori and Pacific people. JNZS 2015;20:24.

26 Saville-Smith N, Saville-Smith K. Declining egalitarianism and the battle for affordable housing in New Zealand. National Science Challenges Building Better Homes, Towns and Cities Ko ngā, 2018.

27 Johnson A, Howden-Chapman P, Eaqub S. A stocktake of New Zealand's housing. Ministry of Business, Innovation \& Employment, 2018.

28 Houkamau CA, Sibley CG. Looking Māori predicts decreased rates of home ownership: institutional racism in housing based on perceived appearance. PLoS One 2015;10:e0118540

29 Jiang N, Pacheco G, Dasgupta K. Understanding the transient population: insights from linked administrative data. J Popul Res 2019;36:111-36.

30 Statistics New Zealand. Perceptions of housing quality in 2010/11 exploratory findings from the New Zealand General social survey. Statistics New Zealand Wellington, 2013.

31 Baker MG, Barnard LT, Kvalsvig A, et al. Increasing incidence of serious infectious diseases and inequalities in New Zealand: a national epidemiological study. Lancet 2012;379:1112-9.

32 Tobias MI, Cheung J. Monitoring health inequalities: life expectancy and small area deprivation in New Zealand. Popul Health Metr 2003;1:2.

33 Stats New Zealand. Census totals by topic, 2013. Available: http:// archive.stats.govt.nz/Census/2013-census/data-tables/total-bytopic.aspx [Accessed 19 Nov 2019]

34 McLeod K. Where we come from, where we Go-Describing population change in New Zealand. New Zealand Treasury Analytical Paper 2018;18.

35 Jiang N, Pacheco G, Dasgupta K. Residential movement within New Zealand: Quantifying and characterising the transient population. Social Policy Evaluation and Research Unit, 2018.

36 Anderson Set al. Residential mobility among children: a framework for child and family policy. Cityscape 2014;16:5-36.

37 Statistics New Zealand. Migration and age, 2013. Available: http:// archive.stats.govt.nz/browse_for_stats/population/Migration/ internal-migration/migration-and-age.aspx [Accessed 19 Nov, 2020].

38 Morton SMBet al. Growing up in New Zealand: a longitudinal study of new Zealand children and their families. now we are four: describing the preschool years. Growing Up in New Zealand: Auckland, 2017.

39 Flouri E, Mavroveli S, Midouhas E. Residential mobility, neighbourhood deprivation and children's behaviour in the UK Health Place 2013;20:25-31. 
40 Gibb S, Das SR. Quality of geographic information in the integrated data infrastructure. Statistics New Zealand, 2015.

41 Atkinson J, Salmond C, Crampton P. NZDep2013 index of deprivation. Wellington: Department of Public Health, University of Otago, 2014.

42 Milne BJ, Atkinson J, Blakely T, et al. Data resource profile: the New Zealand integrated data infrastructure (IDI). Int J Epidemiol 2019;48:677-677e.

43 Reid G, Bycroft C, Gleisner F. Comparison of ethnicity information in administrative data and the census. Wellington, New Zealand: Statistics New Zealand, 2016.

44 Goodyear RK. The differences within: diversity in age structure between and within ethnic groups. Statistics New Zealand Wellington, 2009.

45 Statistics New Zealand,. Statistical standard for geographic areas 2018, S.N. Zealand, editor. 2017: website.

46 Kukutai T. Ethnic Self-Prioritisation of dual and multi-ethnic youth in New Zealand: a discussion paper. Statistics New Zealand, 2008.

47 Whigham PA, de Graaf B, Srivastava R, et al. Managing distance and covariate information with point-based clustering. BMC Med Res Methodol 2016;16:115.
48 Statistics New Zealand. Census 2018, 2018. Available: http:// nzdotstat.stats.govt.nz/wbos/Index.aspx?_ga=2.84774937. 1096428504.1603851586-2545165.1580426634

49 Goodyear R. A place to call home? Declining home-ownership rates for Māori and Pacific peoples in New Zealand. New Zealand Population Review 2017;43:3-34.

50 Perry B. Household incomes in New Zealand: trends in indicators of inequality and hardship 1982 to 2018. Wellington: Ministry of Social Development, 2019.

51 Baker MG, Gurney J, Oliver J, et al. Risk factors for acute rheumatic fever: literature review and protocol for a case-control study in New Zealand. Int J Environ Res Public Health 2019;16:4515.

52 Healthy homes guarantee act 2017.

53 Residential Tenancies Amendment bill 2020:218-2.

54 Government confirms $\$ 500$ million investment into upgrading state homes. Radio New Zealand 2020 30/07/2020. Available: https:// www.rnz.co.nz/news/political/422336/government-confirms-500 million-investment-into-upgrading-state-homes

55 Statistics New Zealand. Experimental population estimates from linked administrative data: 2017 release. Statistics New Zealand, Tatauranga Aotearoa Wellington, New Zealand, 2017. 